\title{
Dynamic relationship between surrogates of skeletal muscle mass and MELD-Na score in three cirrhotic patients under cell-free and concentrated ascites reinfusion therapy
}

\author{
Yoshiyuki Nakatsuji, ${ }^{1}$ Kaori Yamamoto, ${ }^{1}$ Mitsutaka Yoshizawa ${ }^{2}$
}

'Department of

Gastroenterology, Marunouchi Hospital, Matsumoto, Nagano, Japan

${ }^{2}$ Department of Clinical Engineering, Marunouchi Hospital, Matsumoto, Nagano Prefecture, Japan

\section{Correspondence to} Dr Yoshiyuki Nakatsuij; nakatsuji_y@marunouchi.or.jp

Accepted 23 November 2021

Check for updates

(c) BMJ Publishing Group Limited 2022. No commercial re-use. See rights and permissions. Published by BMJ.

\footnotetext{
To cite: Nakatsuji Y,

Yamamoto K,

Yoshizawa M. BMJ Case

Rep 2022;15:e247129.

doi:10.1136/bcr-2021-

247129
}

\section{DESCRIPTION}

We studied the relationship of the score of model for end-stage liver disease with incorporated serum sodium concentration (MELD-Na) with parameters on sarcopenia using bioelectrical impedance analysis (BIA: InBody770, Inbody Japan Inc., Tokyo) in patients undergoing cellfree and concentrated ascites reinfusion therapy (CART).${ }^{1-3}$ When BIA was not available in a patient, serum creatinine (SCr; normal range:
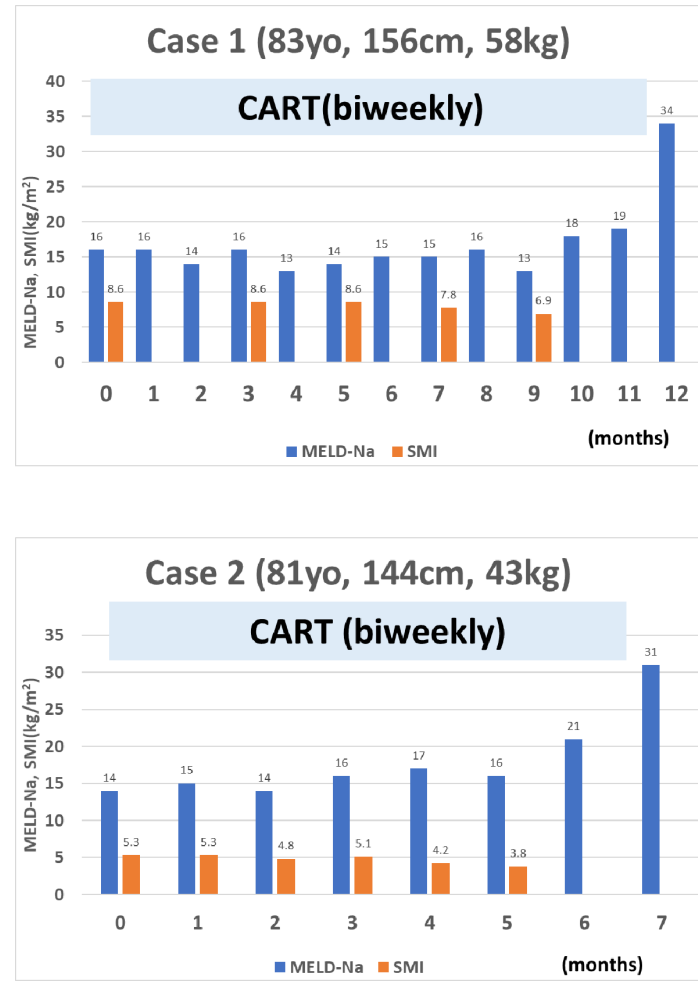

Figure 1 Clinical courses of case 1 and case 2. In case 1 , the bending points were at 9 months of model for endstage liver disease with serum sodium (MELD-Na) score and at 5 months of skeletal muscle index (SMI). In case 2, the bending points were at 5 months of MELD-Na score and at 3 months of SMI. The SMls at 12 months in case 1 and at 6 and 7 months in case 2 were not available due to deterioration of the patient's condition. All the data of MELD-Na in case 1 have been measured and written on a graph. The measured grip strength was $22.0 \mathrm{~kg}$ on the right and $22.1 \mathrm{~kg}$ on the left in case $1,19.0 \mathrm{~kg}$ on the right and $18.8 \mathrm{~kg}$ on the left in case 2 .
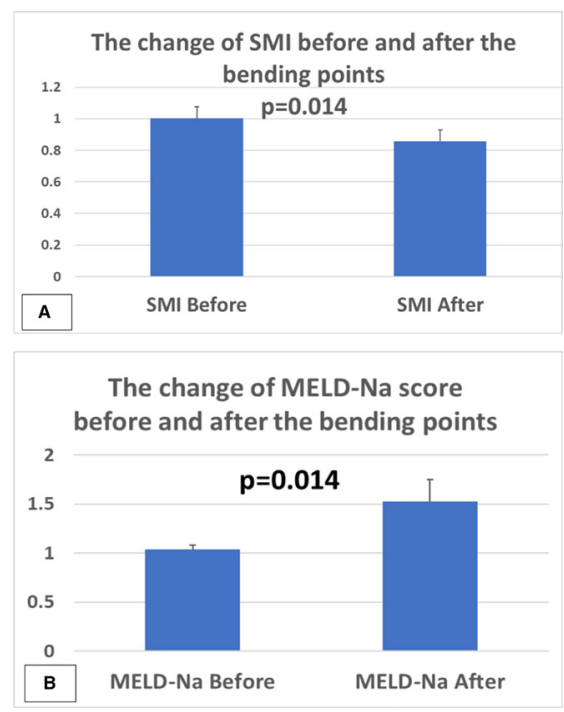

Figure 2 The changes of skeletal muscle index (SMI) and model for end-stage liver disease with serum sodium (MELD-Na) score before and after the respective bending points. The error bars represent the standard errors. The values of SMI or MELD-Na score at the bending points were set to 1, respectively. (A) Student's t-test showed significant difference of $p=0.014$ between SMI before $(n=7)$ and after $(n=6)$ the bending points. (B) Student's $t$-test showed significant difference of $p=0.014$ between MELD-Na score before $(n=11)$ and after $(n=7)$ the bending points.

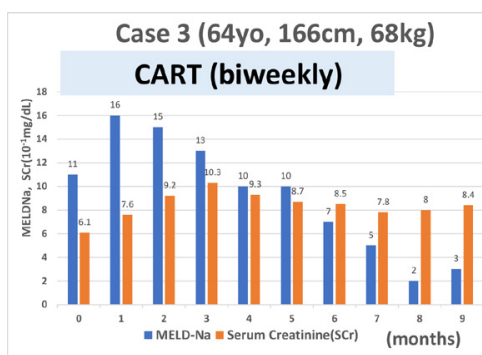

Figure 3 Clinical course of case 3. The unit for serum creatinine is $10^{-1} \mathrm{mg} / \mathrm{dL}$. The cell-free and concentrated ascites reinfusion therapy implementation period was completed by 7 months. The measured grip strength was $25.5 \mathrm{~kg}$ on the right and $25.0 \mathrm{~kg}$ on the left in case 3 . An irregularly measured skeletal muscle index level showed $6.9 \mathrm{~kg} / \mathrm{m}^{2}$. 

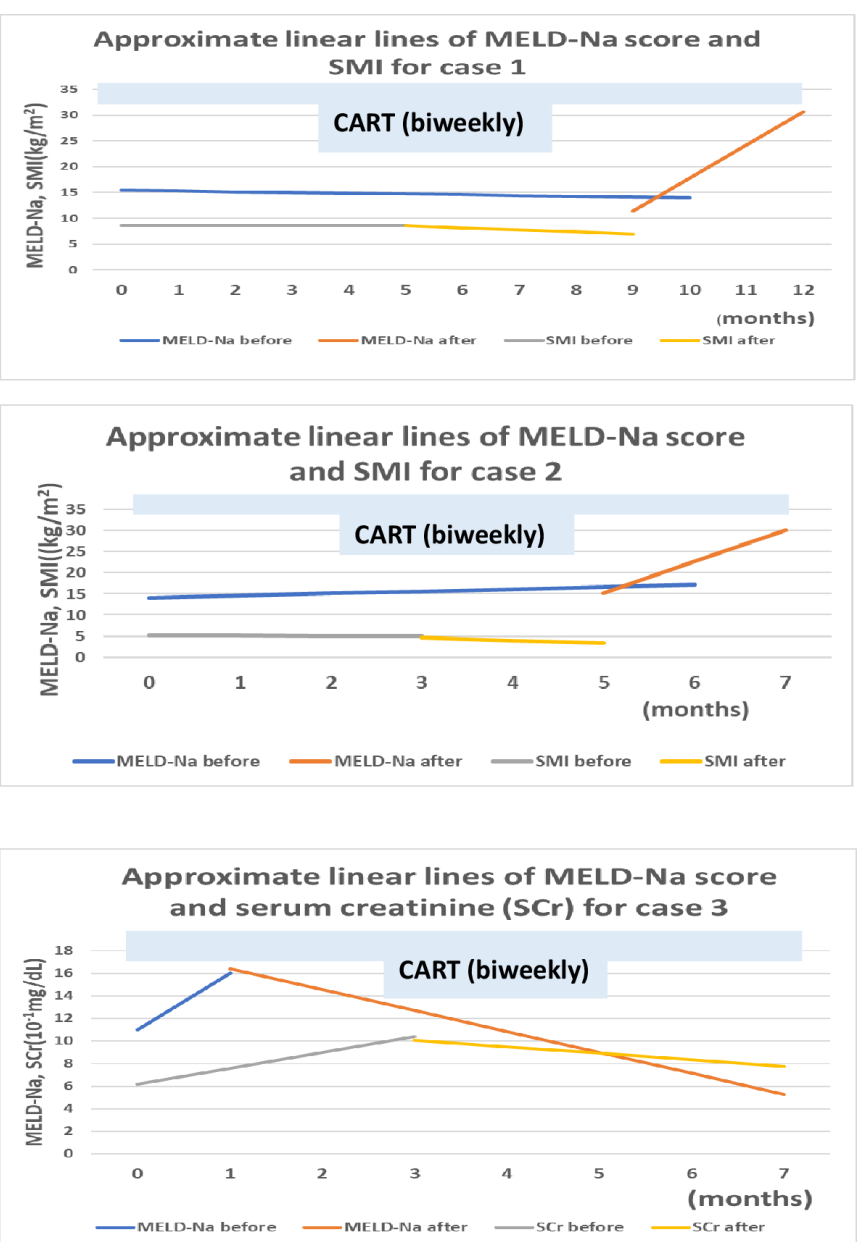

Figure 4 Approximate linear lines of model for end-stage liver disease with serum sodium (MELD-Na) score and skeletal muscle index (SMI) or serum creatinine ( $\mathrm{SCr}$ ) for case 1, case 2 and case 3. MELD$\mathrm{Na}$ before, $\mathrm{SMI}$ before and $\mathrm{SCr}$ before represent the approximate lines before the respective bending points, and MELD-Na after, SMI after and $\mathrm{SCr}$ after represent the approximate lines after the respective bending points. The $\mathrm{R}^{2}$ means the coefficient of determination, which ranges between 0.8325 and 1 . The vertical axis indicates the $y$ coordinate, and the horizontal axis indicates the $x$-coordinate. In case 1; MELD-Na before: $y=-0.1455 x+15.4546\left(R^{2}=0.9643\right)$, MELD-Na after: $y=6.4 x-46.2\left(R^{2}=0.8325\right)$. In case 1 ; SMI before: $y=8.6$, SMI after: $y=-0.425 x+10.7417\left(R^{2}=0.9988\right)$. In case 2; MELD-Na before: $y=0.5143 x+14.0476\left(R^{2}=0.9868\right)$, MELD-Na after: $y=7.5 x-22.3333$ $\left(R^{2}=0.9643\right)$. In case 2 ; SMI before: $y=-0.11 x+5.29\left(R^{2}=0.9868\right)$, SMI after: $y=-0.65 x+6.5666\left(R^{2}=0.9530\right)$. In case 3; MELD-Na before: $y=5 x+11\left(R^{2}=1\right)$, MELD-Na after: $y=-1.8571 x+18.2857$ $\left(R^{2}=0.9769\right)$. In case 3; SCr before: $y=1.42 x+6.17\left(R^{2}=0.9943\right), S C r$ after: $y=-0.58 x+11.82\left(R^{2}=0.9625\right)$ (originally, $y=0.142 x+0.617$, $y=-0.058 x+1.182$.

0.63-1.05 mg/dL) was used as a surrogate marker for skeletal muscle mass. ${ }^{4}$ Sarcopenia was reported to reduce life quality and worsen prognosis with liver cirrhosis (LC). ${ }^{5}$ Our three male patients suffered from decompensated LC, case 1 with non-alcoholic steatohepatitis with type 2 diabetes mellitus at age 83 , case 2 with alcoholic liver disease with primary biliary cholangitis at age 81 and case 3 with alcoholic LC at age 64. They had CART administrations almost every 2 weeks to control ascites. BIA was performed every 1-3 months to estimate their nutritional states, and calculated

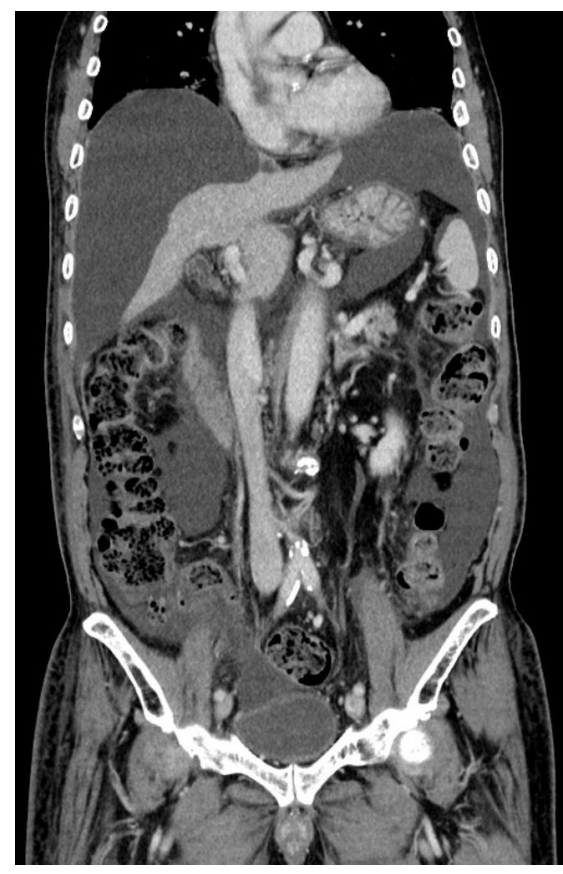

Figure 5 Coronal abdominal CT at porta hepatis showed that the liver area size was $4888 \mathrm{~mm}^{2}$ in case 1 .

skeletal muscle index (SMI: (skeletal muscle mass)/(body height $)^{2}, \mathrm{~kg} / \mathrm{m}^{2}$ ). Handgrip strength was assessed with a digital grip strength dynamometer (T.K.K.5401 GRIP D; Takei Scientific Instruments, Niigata, Japan). Sarcopenia was diagnosed using the Japan Society of Hepatology criteria, and defined as grip strength $<26 \mathrm{~kg}$ and SMI $<7.0 \mathrm{~kg} / \mathrm{m}^{2}$ for man in $2016 .^{6}$ As a result, SMI and MELD-Na score showed reciprocal trends, with the MELD-Na score beginning to rise 2-4 months after SMI began to decline (figure 1 ). The bending points were considered as the boundary between the

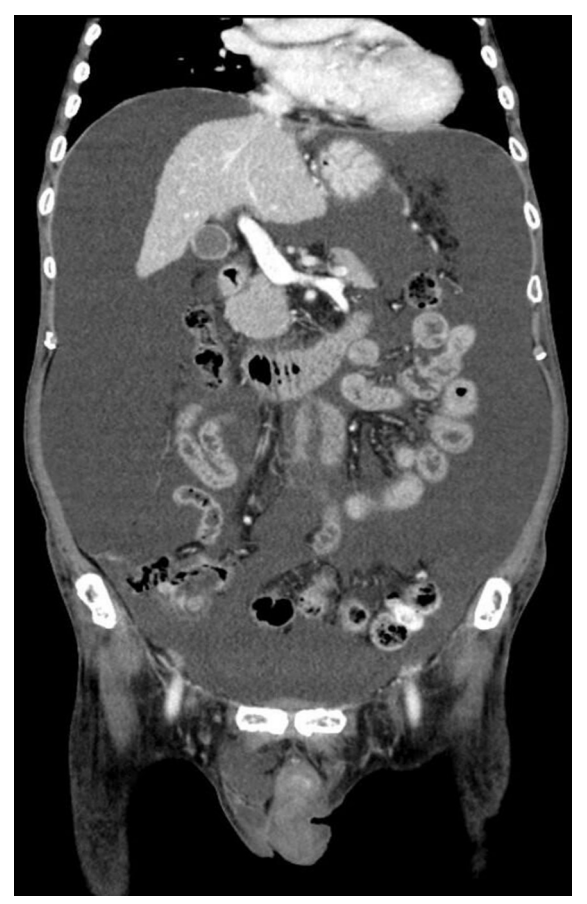

Figure 6 Coronal abdominal CT at porta hepatis showed that the liver area size was $5894 \mathrm{~mm}^{2}$ in case 2 . 


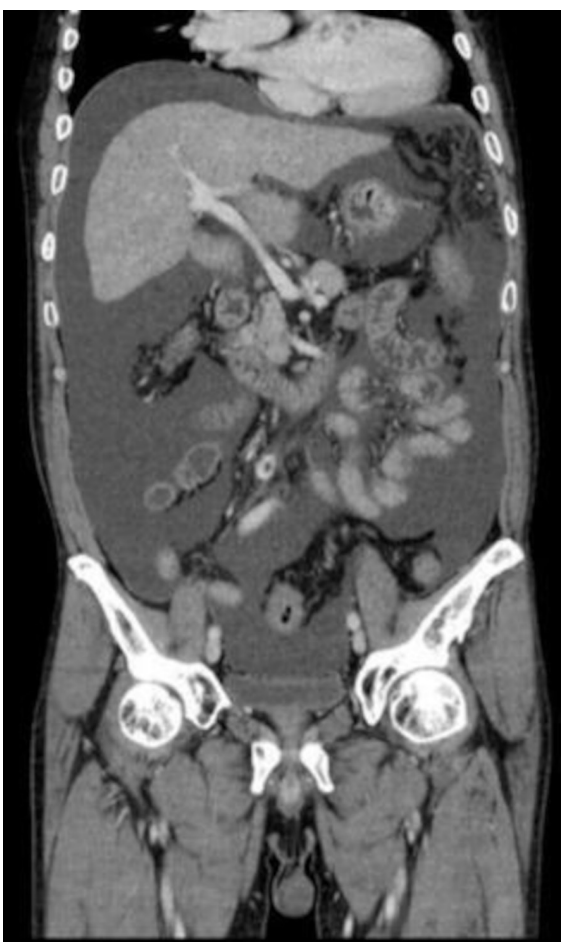

Figure 7 Coronal abdominal CT at porta hepatis showed that the liver area size was $13271 \mathrm{~mm}^{2}$ in case 3 .

\section{Patient's perspective}

Case 1: My husband was not a heavy drinker, but he has been treated for diabetes mellitus since he was in his $30 \mathrm{~s}$. He is currently undergoing self-injection of insulin, and his total daily insulin dose is about 50 units. He was obese from a young age, his job was as a salesman, and he often ate out a lot. In that sense, I think it was a lifestyle-related disease.

\section{Learning points}

- Sarcopenia has been reported to be associated with worse prognosis in cirrhosis. In case 1 and case 2, we reported an increase in model for end-stage liver disease with serum sodium (MELD-Na) score after several months of muscle mass (skeletal muscle index) loss during cell-free and concentrated ascites reinfusion therapy (CART).

- In case 3, a cirrhotic patient with normal kidney function had a decrease in MELD-Na score and a concomitant gradual increase in serum creatinine ( $\mathrm{SCr}$ ) under CART. This means that if $\mathrm{SCr}$ reflects skeletal muscle mass without excess or deficiency, then the contraposition to the proposition 'If skeletal muscle mass decreases, MELD-Na score increases under CART', that is, 'If MELD-Na score decreases, skeletal muscle mass ( $\mathrm{SCr}$ ) increases under CART' is valid.

- Elevated serum myostatin levels have been reported to be associated with skeletal muscle mass loss and poor survival in cirrhotic patients, and although the involvement of cytokines was not examined in this paper, future studies of cytokine dynamics on sarcopenia in serum and ascites during CART are expected. two trends. Significant differences on SMI and MELD-Na score were confirmed by Student's t-test/Mann-Whitney U test before and after the bending points during each course with $\mathrm{p}=0.014 / \mathrm{p}<0.05$ and $\mathrm{p}=0.014 / \mathrm{p}<0.05$, respectively (figure 2). The values at the bending points were set to 1 . A $p$ value of $<0.05$ was considered statistically significant (XLSTAT 2016: Addinsoft Inc., NY, USA). Case 3 showed that SCr peaked at a few months after the MELD-Na score began to decrease with normal kidney function (figure 3). Figure 4 showed that the time courses of MELD-Na score and surrogate markers of muscle mass in each case were well approximated by linear lines. All three patients were diagnosed with sarcopenia. The molecular weight (MW) of myostatin was reported to be $26 \mathrm{kDa}$, in comparing with albumin of $66 \mathrm{kDa}^{7}$ CART's filters for concentration are supposed to be able to concentrate molecules with the MW of $30 \mathrm{kDa}$ or more. When compared imagingly, abdominal computed tomography (CT) showed that the liver area size $\left(13271 \mathrm{~mm}^{2}\right)$ of case 3 was as 2.2-2.7 times as those of case $1\left(4888 \mathrm{~mm}^{2}\right)$ and case $2\left(5894 \mathrm{~mm}^{2}\right)$ (figures $\left.5-7\right)$. These imaging studies would suggest that the liver size might be one factor in the ability of MELD-Na to improve as well as the age difference, which in turn might be linked to increased muscle mass. Detailed research on the molecular level of sarcopenia and LC under CART is expected in the future.

Acknowledgements The authors would like to thank all medical staff in our hospital for their help. Especially, we also would like to thank Dr Kendo Kiyosawa at Department of Internal Medicine of Aizawa Higashi Hospital for his helpful discussions.

Contributors YN conceived the study and wrote the manuscript. KY helped writing the manuscript. MY performed the CART and provided critical intellectual support in finalising the manuscript.

Funding The authors have not declared a specific grant for this research from any funding agency in the public, commercial or not-for-profit sectors.

Competing interests None declared.

Patient consent for publication Consent obtained from next of kin.

Provenance and peer review Not commissioned; externally peer reviewed.

Case reports provide a valuable learning resource for the scientific community and can indicate areas of interest for future research. They should not be used in isolation to guide treatment choices or public health policy.

\section{REFERENCES}

1 Biggins SW, Kim WR, Terrault NA, et al. Evidence-Based incorporation of serum sodium concentration into MELD. Gastroenterology 2006;130:1652-60.

2 Janssen I, Heymsfield SB, Baumgartner RN, et al. Estimation of skeletal muscle mass by bioelectrical impedance analysis. J App/ Physiol 2000;89:465-71

3 Yoshizawa M, Nakatsuji Y. Improvement of major problems in the cell-free and concentrated ascites reinfusion therapy system using external pressure for filtration. Ther Apher Dial 2019:23:233-6.

4 Schutte JE, Longhurst JC, Gaffney FA, et al. Total plasma creatinine: an accurate measure of total striated muscle mass. J App/ Physiol Respir Environ Exerc Physiol 1981;51:762-6

5 Hanai T, Shiraki M, Nishimura K, et al. Sarcopenia impairs prognosis of patients with liver cirrhosis. Nutrition 2015;31:193-9.

6 Nishikawa H, Shiraki M, Hiramatsu A, et al. Japan Society of hepatology guidelines for sarcopenia in liver disease (1st edition): recommendation from the Working group for creation of sarcopenia assessment criteria. Hepatol Res 2016;46:951-63.

7 Nishikawa $\mathrm{H}$, Enomoto $\mathrm{H}$, Ishii $\mathrm{A}$, et al. Elevated serum myostatin level is associated with worse survival in patients with liver cirrhosis. J Cachexia Sarcopenia Muscle 2017:8:915-25 
Copyright 2022 BMJ Publishing Group. All rights reserved. For permission to reuse any of this content visit https://www.bmj.com/company/products-services/rights-and-licensing/permissions/

BMJ Case Report Fellows may re-use this article for personal use and teaching without any further permission.

Become a Fellow of BMJ Case Reports today and you can:

- Submit as many cases as you like

Enjoy fast sympathetic peer review and rapid publication of accepted articles

Access all the published articles

Re-use any of the published material for personal use and teaching without further permission

Customer Service

If you have any further queries about your subscription, please contact our customer services team on +44 (0) 2071111105 or via email at support@bmj.com.

Visit casereports.bmj.com for more articles like this and to become a Fellow 